\title{
Influência do período e das condições de armazenamento de feijão no tempo de cocção ${ }^{1}$
}

\author{
Influence of the period and storage conditions of beans at the time of cooking
}

\author{
Pedro Patric Pinho Morais ${ }^{2}$, Giseli Valentini², Altamir Frederico Guidolin ${ }^{2 *}$, Joana Neres da Cruz Baldissera² e \\ Jefferson Luís Meirelles Coimbra²
}

\begin{abstract}
Resumo - A utilização de técnicas adequadas de armazenamento permite a conservação da qualidade nutricional e tecnológica dos grãos por períodos prolongados. Sendo assim, o objetivo desse trabalho foi avaliar o efeito de diferentes condições e tempos de armazenamento no caráter tempo de cocção dos grãos de feijão. Os tratamentos foram constituídos de cinco períodos de armazenamento $(0 ; 45 ; 90 ; 180$ e 360 dias) em quatro condições de armazenamento (1: embalagem de polietileno em câmara fria; 2: embalagem de polietileno em temperatura ambiente; 3: papel em câmara fria; 4: papel em temperatura ambiente), para dois genótipos (BRS Supremo e Pérola), dispostos em fatorial 5 x 4 × 2, em delineamento experimental de blocos casualizados, com quatro repetições. Foi realizado o teste de cocção para cada unidade experimental e sendo submetidos à análise de variância pelo teste F. A análise de variância revelou efeito significativo para a interação tripla entre os fatores genótipo, condição de armazenamento e tempo de armazenamento ( $\mathrm{G} \mathrm{x} \mathrm{C} \mathrm{x} \mathrm{A).} \mathrm{Em} \mathrm{condição} \mathrm{de} \mathrm{câmara} \mathrm{fria,} \mathrm{o} \mathrm{tempo} \mathrm{de} \mathrm{cocção} \mathrm{manteve-se} \mathrm{constante}$ durante o período avaliado, independentemente da embalagem utilizada. O tempo de cocção dos grãos de feijão aumenta com o tempo de armazenamento em temperatura ambiente, porém, o ritmo de aumento do tempo de cocção é menor quando os grãos são armazenados em condições herméticas.
\end{abstract}

Palavras-chave - Phaseolus vulgaris L. Tempo de cozimento. Armazenamento de grãos.

\begin{abstract}
The use of appropriate storage techniques preserve the nutritional and technological quality of grain. The objective of this study was to evaluate the effects of storage conditions and storage periods in bean cooking time character. The composition of treatments were five storage periods $(0 ; 45 ; 90 ; 180$ and 360 days) in four storage conditions (1: packing of polythene in cold chamber; 2: packing of polythene in environment temperature; 3: paper packing in cold chamber; 4: paper packing in environment temperature), for two genotypes (BRS Supremo and Pérola). The experiment was conducted in a randomized block design, as a factorial ( $5 \times 4 \times 2)$ arrangement, with four replications. The cooking time was determined to each experimental unit. The results were submitted to variance analysis by the $\mathrm{F}$ test. The variance analysis showed significance to triple interaction between genotypes, storage conditions and storage period $(\mathrm{G} \times \mathrm{C} \times \mathrm{A})$. The cooking time was the same during the evaluated period, when bean grains ware stored in cold chamber, independently of storage conditions. When bean grains ware stored at environment temperature, the cooking time increases along the period; however, the rhythm of increase in cooking time is smaller when the grains are stored in hermetic conditions.
\end{abstract}

Key words - Phaseolus vulgaris L. Time of cooking. Storage environment.

\footnotetext{
* Autor para correspondência

'Recebido para publicação em 10/08/2009; aprovado em 26/09/2010

Pesquisa fianciada pela UDESC, CNPq, CAPES e FAPESC

${ }^{2}$ Departamento de Agronomia, Instituto de Melhoramento e Genética Molecular-IMEGEM, Universidade do Estado de Santa Catarina, Av. Luiz de Camões nº 2.090, Lages-SC, Brasil, 88.520-000, a2afg@cav.udesc.br
} 


\section{Introdução}

O feijão é cultivado em todo o território brasileiro, destacando-se na região Sul como uma cultura importante por apresentar ciclo curto e rápido retorno do investimento. Desempenha não só uma função econômica, mas também social, por inserir grande parte dos pequenos agricultores na cadeia produtiva. É também um dos principais alimentos da dieta brasileira, devido aos seus teores de proteína e microminerais como ferro e zinco (RIBEIRO et al., 2008).

Mesmo com excelentes características nutricionais, o consumo de feijão tem diminuído, tendo como possíveis causas o menor tempo disponível para o preparo das refeições (RAMOS JUNIOR et al., 2005). O feijão é um produto que perde rapidamente o valor comercial após a colheita, principalmente pela redução da capacidade de reidratação, do aumento do tempo necessário de cozimento e do escurecimento do tegumento (RIBEIRO et al., 2007). Por este motivo, é necessário o desenvolvimento de cultivares com qualidades tecnológicas superiores, com menor tempo de cocção. A qualidade nutricional e tecnológica é determinada pelo genótipo e influenciada pelos fatores de ambiente que ocorrem durante $o$ crescimento da planta e desenvolvimento da semente. Os inúmeros fatores de ambiente que influenciam a qualidade do feijão incluem as altas e baixas temperaturas na fase de enchimento de grãos, manejo da cultura, beneficiamento e pós-colheita, condições de estocagem e tecnologia de processamento (DALLA CORTE et al., 2003).

O caráter tempo de cocção é influenciado por diversos fatores, dentre eles o tempo de armazenamento, o qual reflete no grau de dureza dos grãos em decorrência do decréscimo da qualidade fisiológica (SARTORI et al., 1996). Associado ao aumento do tempo de cozimento com o armazenamento, o feijão perde gradativamente algumas qualidades sensoriais, as quais se caracterizam por mudanças no sabor, endurecimento do tegumento, aumento do grau de dureza do grão, dentre outras (REYESMORENO; PAREDEZ-LOPEZ, 1993).

O tempo de cocção relaciona-se com a capacidade de penetração de água nos grãos que pode ser devido a efeitos de impermeabilidade do tegumento do feijão à água, causando uma hidratação mais lenta durante o cozimento. $\mathrm{Ou}$ ainda, pode ser devido à impermeabilidade dos cotilédones à água, em razão das modificações químicas que ocorrem durante o armazenamento (CASTELLANOS et al., 1995). Estes fatores estão relacionados às embalagens utilizadas. A temperatura e a umidade relativa durante o armazenamento afetam a qualidade do feijão para o cozimento, pois maior tempo de cocção se faz necessário à medida que se aumenta o período de estocagem dos grãos. Condições de armazenamento em alta temperatura e umidade promovem a troca de umidade dos grãos com o ambiente, e induzem a alterações na integridade do tegumento dos grãos e na qualidade fisiológica (MARCOS FILHO, 2005; TORRES, 2005).

A deterioração de grãos de feijão está relacionada com o tempo de armazenamento e com as condições de embalagem e ambiente de armazenamento. O objetivo desse trabalho foi avaliar o efeito de diferentes condições e tempos de armazenamento no caráter tempo de cocção dos grãos de feijão.

\section{Material e métodos}

$\mathrm{O}$ experimento foi realizado no Instituto de Melhoramento e Genética Molecular(IMEGEM) do Centro de Ciências Agroveterinárias (CAV) da Universidade do Estado de Santa Catarina (UDESC) em Lages estado de Santa Catarina. Foram utilizados dois genótipos de feijão, sendo um do grupo comercial preto (BRS Supremo) e um do grupo carioca (Pérola). Os grãos foram obtidos do ensaio de valor de cultivo e uso (VCU) do Estado de Santa Catarina, localizado na cidade de Lages, em uma altitude de 916 m. Após a colheita, os grãos foram secos e sua umidade padronizada para $13 \%$ em câmara seca.

Os tratamentos foram constituídos de cinco períodos de armazenamento $(0 ; 45 ; 90,180$ e 360 dias $)$ em quatro condições de armazenamento: 1: embalagem de polietileno em câmara fria; 2 : embalagem de polietileno em temperatura ambiente; 3: papel em câmara fria; e 4: papel em temperatura ambiente. As embalagens de polietileno utilizadas foram garrafas de polietileno tereftalato (PET), as quais foram fechadas hermeticamente e armazenadas em câmara fria (temperatura média do ar de $8^{\circ} \mathrm{C}$ e umidade relativa de $45 \%$ ) e em temperatura ambiente (temperatura do ar variando de 36 e $-7,4{ }^{\circ} \mathrm{C}$ e umidade relativa média de $79,3 \%$ ), sendo as mesmas condições proporcionadas para as embalagens de papel. O delineamento experimental utilizado foi blocos casualizados com quatro repetições, onde todos os tratamentos foram distribuídos num esquema fatorial de $5 \times 4 \times 2$.

Cada uma das combinações possíveis foi avaliada quanto ao tempo de cocção, o qual consistiu na hidratação dos grãos por 12 horas a $25^{\circ} \mathrm{C}$. Uma amostra de 25 grãos para cada repetição foi utilizada para o teste de cocção, utilizando o aparelho de cocção de Mattson, adaptado por Proctor e Watts (1987). A amostra de 25 grãos hidratados de feijão foi colocada sobre o suporte do aparelho, ficando cada haste sobre um grão. Após este procedimento o aparelho foi então colocado em recipiente contendo água destilada fervente. O cozimento completo foi considerado quando $50 \%$ mais 1 (um) dos grãos foram perfurados, ou seja, a queda de $52 \%$ das hastes.

Os dados foram submetidos à análise de variância pelo teste $F$ global para testar as hipóteses 
dos efeitos principais e da interação entre os fatores. Quando o efeito da interação foi significativo, os graus de liberdade foram desdobrados, ajustando curvas de regressão (COIMBRA et al., 2004) através do programa estatístico SAS 9.1.3 (2007).

\section{Resultados e discussão}

A análise de variância (TAB. 1) apresenta os valores referentes aos efeitos principais e a interação entre os fatores, a qual revelou efeito significativo dos efeitos principais para período de armazenamento (A) e condições de armazenamento (C). A razão entre os quadrados médios não revela influência dos efeitos principais de genótipo para o tempo de cocção, sendo a maior contribuição relacionada aos efeitos do tempo de armazenamento e às condições de armazenamento. Embora os genótipos não tenham influenciado nos resultados, Carbonell et al. (2003) citam que diferenças entre genótipos de feijão quanto a qualidade tecnológica tem sido reportada em vários programas de melhoramento nacional. No entanto, Bertoldo et al. (2009a) e Bertoldo (2008) afirmam que a contribuição genotípica para o caráter tempo de cocção é baixa, sendo que grande parte da variabilidade observada em seu estudo pode ser atribuída ao efeito de ambiente e da interação genótipo e ambiente. De acordo com a mesma tabela, pode-se verificar que houve interação tripla entre os fatores genótipo $(\mathrm{G})$, condição de armazenamento $(C)$ e tempo de armazenamento $(\mathrm{A})$ : ( $\mathrm{G}$ x C x A) para a variável tempo de cocção, indicando comportamento diferenciado em função do genótipo, da condição de armazenamento e do tempo de armazenamento.

A interação tripla foi significativa (TAB. 1), porém os dados revelam que a maior contribuição para que este efeito tenha se mostrado significativo deve-se ao efeito do armazenamento e das condições de armazenamento, visto a amplitude do quadrado médio para a interação dupla (A x C).

Na Figura 1 observou-se o efeito do tempo de cocção ao se variar o tempo de armazenamento e fixar os fatores genótipo e condições de armazenamento. Para o armazenamento em ambiente controlado de câmara fria (FIG. 1A, 1C, 1E e $1 \mathrm{G})$, nenhum genótipo, em qualquer uma das embalagens utilizadas, apresentou valores significativos, indicando que em ambiente com temperatura e umidade baixas, se conserva a qualidade fisiológica e tecnológica dos grãos de feijão, mantendo constante o tempo de cocção e as características tecnológicas por até 360 dias. Nessas condições, o tempo de cocção para o genótipo BRS Supremo foi de 32 minutos quando armazenado em embalagem de polietileno em câmara fria e de e 31 minutos quando armazenado em embalagem de papel na câmara fria. Semelhantemente, o genótipo Pérola, que pertence ao grupo comercial carioca, teve média de 33 minutos para tempo de cocção quando armazenado em embalagem de polietileno em câmara fria e de 33 minutos quando armazenado em embalagem de papel na câmara fria.

Observa-se ainda (FIG. 1) na condição de câmara fria que o tempo de cocção foi semelhante para as duas embalagens utilizadas, polietileno e papel, indicando que o principal fator responsável pela manutenção do tempo de cocção dos grãos de feijão foi o armazenamento em ambiente controlado em câmara fria. Brackmann et al. (2002) também evidenciaram menor tempo de cozimento durante o armazenamento em condições controladas, em relação ao armazenamento convencional. Além disso, em condições de câmara fria, Torres (2005) avaliou armazenamento de sementes de melancia e concluiu ser um eficiente método de conservação durante doze meses, sem perda da qualidade fisiológica, utilizando as embalagens saco plástico, saco de papel ou caixa plástica tipo Tuppewear.

Tabela 1 - Análise de variância para a variável tempo de cocção (minutos) de dois genótipos de feijão, quatro condições de armazenamento e cinco tempos de armazenamento. UDESC - IMEGEM, Lages SC, 2009

\begin{tabular}{lccc}
\hline \multicolumn{1}{c}{ Fontes de variação } & Graus de liberdade & Quadrado Médio & $\operatorname{Pr}>\mathrm{F}$ \\
\hline Bloco & 3 & 28,3 & 0,0604 \\
Genótipo (G) & 1 & 39,0 & 0,0643 \\
Armazenamento (A) & 4 & 1468,9 & $<, 0001$ \\
G x A & 4 & 48,1 & 0,0028 \\
Condição de armazenamento (C) & 3 & 1958,1 & $<, 0001$ \\
G x C & 3 & 5,1 & 0,7152 \\
A x C & 12 & 866,3 & $<, 0001$ \\
G x A x C & 12 & 33,1 & 0,0012 \\
Erro & 117 & 11,2 & \\
\hline \multicolumn{2}{c}{} \\
\hline
\end{tabular}




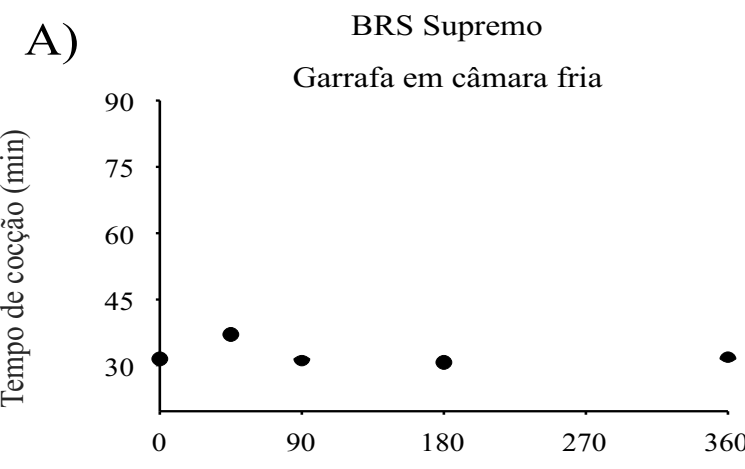

Armazenamento (dias)

C)

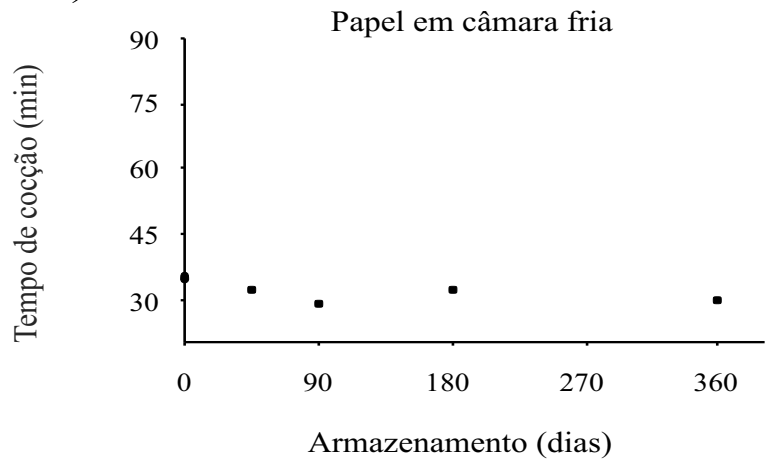

E)

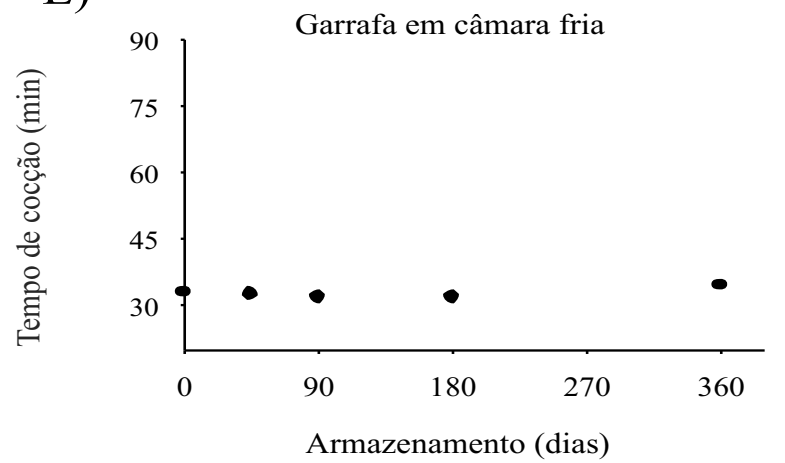

G)

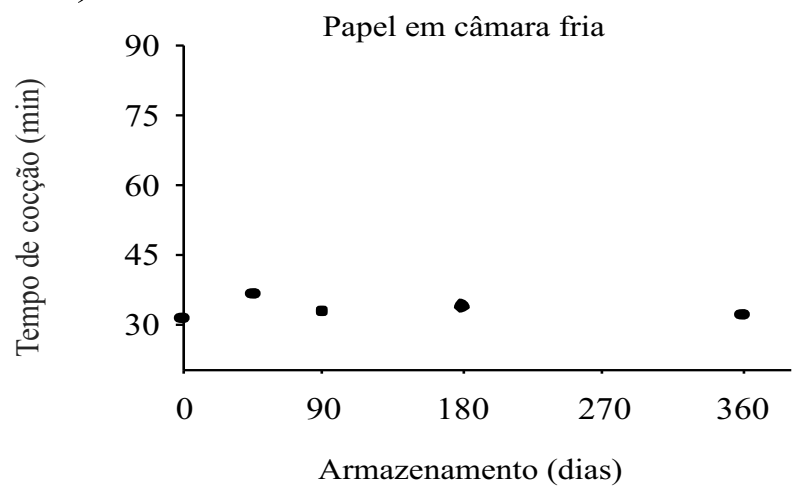

B)

BRS Supremo

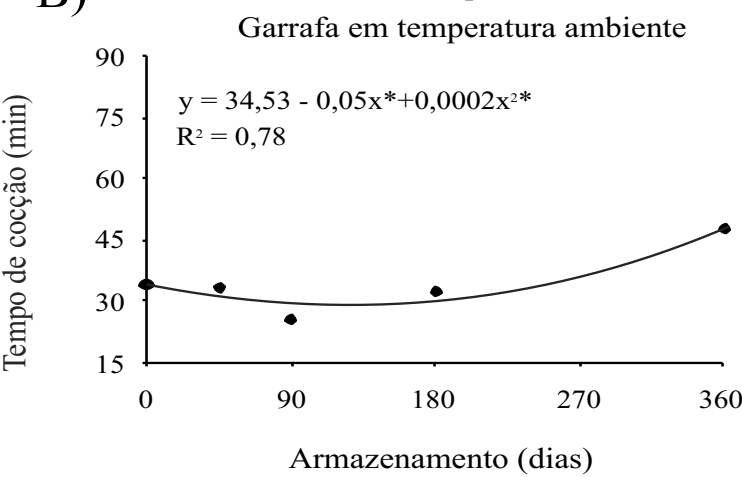

D)

BRS Supremo

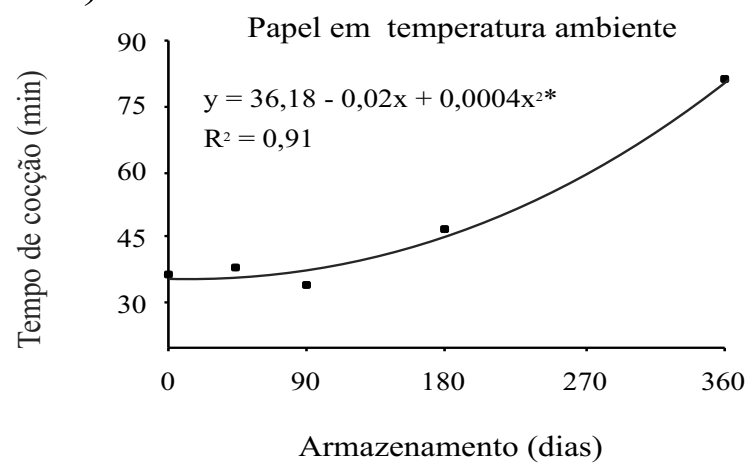

F)

Pérola

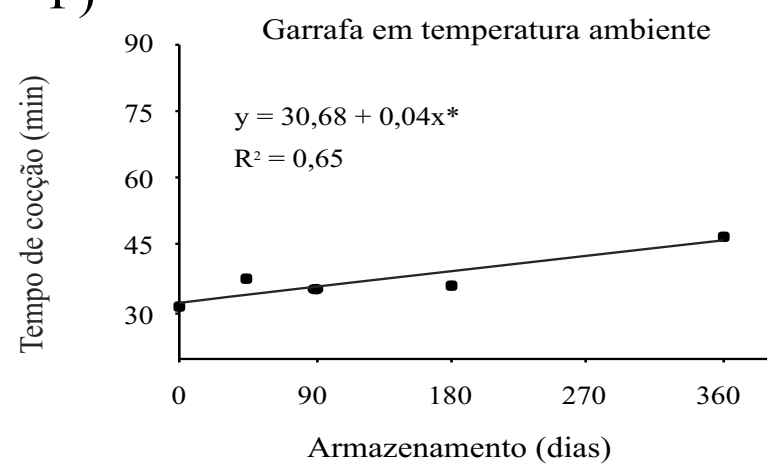

H)

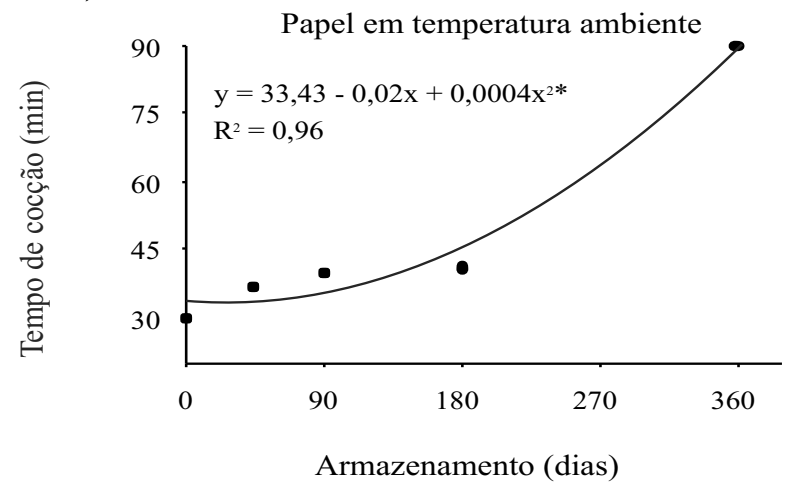

Figura 1 - Comportamento dos genótipos Pérola e BRS Supremo nas diferentes condições de armazenamento, ao longo do tempo de armazenamento para o tempo de cocção (minutos), UDESC - IMEGEM, Lages SC, 2009 
Em condição de temperatura ambiente (FIG. 1B, 1D, $1 \mathrm{~F}$ e $1 \mathrm{H}$ ), houve influência do tempo de armazenamento, sendo que o tempo de cocção aumentou em decorrência do aumento do tempo de armazenamento. A qualidade culinária do feijão é afetada à medida que aumentam os meses após a colheita, sendo que, o tempo de cocção é uma das características culinárias de maior importância para o consumidor, e tem como resultado o aumento considerável em decorrência do período de armazenamento (RIOS et al., 2003). Esse aumento do tempo de cocção dos grãos pode estar relacionado aos fenômenos: hardshell e hard-tocook (BERTOLDO et al., 2009b). O fenômeno hardshell se relaciona com as sementes que não absorvem água suficiente durante o cozimento e, portanto, não amolecem. Isto pode ser devido à baixa permeabilidade do tegumento à água. Hard-to-cook se refere aos grãos que absorvem água suficiente, mas não amolecem mediante hidratação. Isto é resultado de mudanças físicas e químicas que ocorrem nos cotilédones e a níveis intercelulares durante o armazenamento, resultando num aumento na estabilidade da lamela média. Tais processos são afetados durante um longo período de armazenamento (KIGEL, 1999).

Com relação ao armazenamento em temperatura ambiente, pode-se verificar ainda que os genótipos BRS Supremo e Pérola tiveram aumento no tempo de cocção quando armazenados em embalagem de papel (FIG.a 1D e $1 \mathrm{H})$, o que demonstra que houve mudanças fisiológicas nas sementes durante o armazenamento. O genótipo BRS Supremo no tempo zero apresentou tempo de cocção de 36 minutos, passando para 81 minutos aos 360 dias de armazenamento, com aumento de 45 minutos. O genótipo Pérola teve aumento de 60 minutos no tempo de cocção, passando de 30 minutos no tempo zero para 90 minutos aos 360 dias de armazenamento. Nestas condições, com demanda de 81 e 90 minutos para cozimento dos grãos o gasto de tempo e de energia é significativo, podendo tornar o consumo do feijão inviável, especialmente para a dona de casa moderna. Conforme Rodrigues et al. (2005), são desejáveis cultivares de feijão com tempo de cozimento menor do que 30 minutos, pois significa economia de energia, capital e tempo de espera.

A maior influência para o fato da interação tripla $(\mathrm{G} \times \mathrm{A} \times \mathrm{C})$ ter se apresentado significativo deve-se principalmente à grande contribuição do tempo de armazenamento e das condições de armazenamento, principalmente em relação às condições de armazenamento em papel em temperatura ambiente no período de armazenamento de 360 dias. Os valores da estimativa de $\mathrm{R}^{2}$ evidenciados para todos os genótipos em condições de armazenamento em temperatura ambiente (FIG. 1) indicaram que o ajuste do modelo foi eficiente ao explicar a variação do tempo de cocção em função do período de armazenamento.
Nas situações de armazenamento em temperatura ambiente na embalagem de polietileno hermeticamente fechada (FIG. 1B e 1F), houve um aumento do tempo de cocção, sendo de 14 minutos para o genótipo BRS Supremo, passando de 34 minutos no tempo zero para 48 minutos aos 360 dias de armazenamento. O genótipo Pérola teve aumento de 15 minutos, passando de 32 minutos no tempo zero para 47 minutos aos 360 dias. Às condições de temperatura e umidade relativa altas durante o armazenamento influenciam no aumento do tempo de cozimento dos grãos (SAWAZAKI et al., 1985). No sistema de armazenamento hermético, os grãos apresentaram menor variação de umidade devido a não ocorrência de trocas com o ambiente, permitindo a estabilidade da umidade dos grãos (RUPOLHO et al., 2004).

A utilização de técnicas de armazenamento adequadas permite prolongar a conservação da qualidade dos grãos. Aliado a isso, os programas de melhoramento que visam a introdução de novas cultivares devem considerar a seleção de genótipos que apresentem características culinárias adequadas aos consumidos, incluindo um reduzido tempo de cocção.

\section{Conclusões}

1. Os genótipos de tegumento preto e carioca tiveram comportamento semelhante com relação ao tempo de cocção;

2. O tempo de cocção de grãos de feijão armazenados em condições de câmara fria não aumentou com o decorrer do período de armazenamento, se apresentando como alternativa para a conservação dos grãos;

3. O tempo de cocção dos grãos de feijão aumentou com o tempo de armazenamento em temperatura ambiente, porém o ritmo de aumento do tempo de cocção é menor quando os grãos são armazenados em condições herméticas.

\section{Referências}

BERTOLDO, J. G. et al. Correlação entre caracteres de produção e tempo de cocção em feijão em dois ambientes. Revista Ciência Agronômica, v. 40, n. 01, p. 135-140, 2009 a.

BERTOLDO, J. G. et al. Tempo de cocção de grãos de feijão em função de doses de fósforo no plantio e do tempo de armazenamento. Biotemas, v. 22, n. 01, p.39-47, 2009 b.

BERTOLDO, J. G. Melhoramento de feijão para o planalto catarinense: variabilidade genética, consequência da interação e peletização com enfoque na redução do tempo de cocção. 2008. 
76 f. Dissertação (mestrado em Produção Vegetal) - Universidade do Estado de Santa Catarina, Lages.

BRACKMANN, A. et al. Conservação de três genótipos de feijão (Phaseolus vulgaris L.) do grupo carioca em armazenamento refrigerado e em atmosfera controlada. Ciência Rural, v. 32, n. 06, p. 911-915, 2002.

CARBONELL, S. A. M. et al. Qualidade tecnológica de grãos de genótipos de feijoeiro cultivados em diferentes ambientes. Bragantia, v. 62, n. 03, p. 369-379, 2003.

CASTELLANOS, J. Z. et al. Effects of hardshell character on cooking time of common beans grown in the semiarid highlands of Mexico. Journal of the Science of Food and Agriculture, v. 69, n. 04, p. $437-443,1995$.

COIMBRA, J. L. M. et al. Fundamentos do SAS aplicado à experimentação agrícola. Pelotas: Editora e Gráfica Universitária, v. 1, 2004. 236 p.

DALLA CORTE, A. et al. Environment effect on grain quality in early common bean cultivars and lines. Crop Breeding and Applied Biotechnology, v. 03, n. 03, p. 193-202, 2003.

KIGEL, J. Culinary and nutritional quality of Phaseolus vulgaris seeds as affected by evironmental factors. Biotechnologie Agronomie Society Enviroment, v. 03, n. 04, p. 205-209, 1999.

MARCOS FILHO, J. Fisiologia de sementes de plantas cultivadas. Piracicaba: Fealq, 2005. 495 p.

PROCTOR, J. R.; WATTS, B. M. Development of a modified Mattson bean cooker procedure basead on sensory panel cookability evaluation. Canadian Institute of Food Science and Technology Journal, v. 20, n. 01, p. 9-14, 1987.

RAMOS JUNIOR, E. U. et al. Componentes da produção, produtividade de grãos e características tecnológicas de cultivares de feijão. Bragantia, v. 64, n. 01, p. 75-82, 2005.
REYES-MORENO, C; PAREDEZ-LOPEZ, O. Hard to cook phenomenon in common beans: a review. Critical Reviews in Food Science and Nutrition, v. 33, n. 03, p. 227-286, 1993.

RIBEIRO, N. D. et al. Composição de microminerais em cultivares de feijão e aplicações para o melhoramento genético. Bragantia, v. 67, n. 02, p. 267-273, 2008.

RIBEIRO, N. D. et al. Efeito de períodos de semeadura e das condições de armazenamento sobre a qualidade de grãos de feijão para o cozimento. Bragantia, v. 66, n. 01, p. 157-163, 2007.

RIOS, A. O. et al. Efeito da estocagem e das condições de colheita sobre algumas propriedades físicas, químicas e nutricionais de três cultivares de feijão Phaseolus vulgaris L.). Ciência e Tecnologia de Alimentos, v. 23, p. 39-45, 2003. Suplemento.

RODRIGUES, J. A. et al. Qualidade para o cozimento de grãos de feijão obtidos em diferentes épocas de semeadura. Bragantia, v. 64, n. 03 , p. 369-376, 2005.

RUPOLLO, G. et al. Sistemas de armazenamentos hermético e convencional na conservabilidade de grãos de aveia. Ciência Rural, v. 34, n. 06, p. 1715-1722. 2004.

SARTORI, M. R. Armazenamento. In: ARAÚJO, R. S. et al. (Coord). A cultura do feijoeiro comum no Brasil. Piracicaba: Potafos, 1996. p. 543-562.

SAS INSTITUTE INC. SAS 9.1.3 (TS1M3) for Windows Microsoft. Cary, NC: SAS Institute Inc, 2007.

SAWAZAK, H. E. et al. Modificações bioquímicas e físicas em grãos de feijão durante o armazenamento. Bragantia, v. 44, n. 01, p. 375-390, 1985.

TORRES, S. B. Qualidade de sementes de melancia armazenadas em diferentes embalagens e ambientes. Revista Ciência Agronômica, v. 36, n. 02, p. 163-168, 2005. 